\title{
Design and experimental validation of sliding knife notch-type disc opener for a no-till combine harvester cum seed drill
}

\author{
Kuan Qin ${ }^{1}$, Weimin Ding ${ }^{1 *}$, Fiaz Ahmad ${ }^{2}$, Zhichao Fang $^{1}$ \\ (1. College of Engineering, Nanjing Agricultural University, Jiangsu Province, Nanjing 210031, China; \\ 2. Department of Agricultural Engineering, Bahauddin Zakariya University, Multan, Pakistan)
}

\begin{abstract}
One major constraint in developing a combine harvester cum seed drill (CHCSD) is the limited space available for the attachment of no-till furrow openers. Investigating the straw stubble cutting and furrow opening performance of small-sized disc furrow openers is critically important for the development and the optimization of the no-till seeding assemblies. A set of down-scaled sliding knife notch-type disc opener (SKO), modified notch-type disc opener (MNO) and smooth-type disc opener (SDO), with upper size limit of $160 \mathrm{~mm}$, were designed and fabricated for field testing. Experimental results show that for small-sized disc furrow openers of the same type, a larger disc diameter yields a greater furrow depth and width. For small-sized disc furrow openers with an identical diameter, SKOs yield a greater furrow depth and width than MNOs, with SDOs yielding the lowest values. The measured furrow depth and width for an SKO with diameter of $160 \mathrm{~mm}$ are $3.52 \mathrm{~cm}$ and $3.56 \mathrm{~cm}$, respectively, meeting the no-tillage furrowing requirements for a CHCSD. The highest stubble cover rate of $62.5 \%$ is obtained for the SKO with diameter of $160 \mathrm{~mm}$. Therefore, this opener has greater ability to remove stubble from the furrow and seeding band than the other designs. Finally, experimental results of the stubble cutting rates confirm that, for irregularly placed straw and residue, the stubble cutting rate of the SKO with diameter of $160 \mathrm{~mm}$ is the highest at $61.7 \%$.
\end{abstract}

Keywords: no-tillage, small-sized, disc furrow opener, furrow type, stubble removal DOI: $10.25165 /$ j.ijabe.20181104.3498

Citation: Qin K, Ding W M, Ahmad F, Fang Z C. Design and experimental validation of sliding knife notch-type disc opener for a no-till combine harvester cum seed drill. Int J Agric \& Biol Eng, 2018; 11(4): 96-103.

\section{Introduction}

The rice-wheat (R-W) system contributes to one major crop rotating zone of grain food production in China. Conservative and sustainable cultivation of the R-W system has prompted rapid technological development on no-till seeding technologies, which are becoming increasingly popular in the R-W rotating areas ${ }^{[1-3]}$. Among these advancements, the combine harvester cum seed drill (CHCSD) is a recently proposed technology for one-pass no-till operation. The CHCSD combines crop harvesting, furrow opening, straw ditch- gathering returning field and seeding fulfilled with a single machine. The test run for the prototype has proved its technical feasibility of providing a combined solution for one-pass crop harvesting and no-till seeding ${ }^{[4]}$. With this machine, straw stubble can be incorporated directly into ditch returning field and direct seeding of rice and wheat can be completed simultaneously during harvesting, yielding time reduction. This has also improved operational efficiency and reduced the amount of machining performed on the ground, ultimately contributing to operational cost reduction. Performance evaluation of this system

Received date: $2017-05-18 \quad$ Accepted date: 2017-12-03

Biographies: Kuan Qin, $\mathrm{PhD}$, research interests: agricultural mechanization equipment, Email: qinkuan_njau@163.com; Fiaz Ahmad, PhD, Lecturer, research interests: agricultural mechanization equipment, Email: engrfiaz@, yahoo.com; Zhichao Fang, $\mathrm{PhD}$, research interests: agricultural mechanization equipment, Email: zcfang1314@163.com.

*Corresponding authors: Weimin Ding, PhD, Professor, research interests: agricultural mechanization equipment. Department of Electrical Engineering, College of Engineering, Nanjing Agricultural University, No.40 Dianjiangtai Road, Pukou District, Nanjing 210031, China. Tel: +86-25-58606502, Email: wmding@njau.edu.cn. has shown that the minimum soil disturbance is obtained through no-tillage seeding with the CHCSD. Soil disturbance is key for sustainable soil use under conservation tillage. However, compared with seeding in traditional plowing circumstance, the soil of a no-tillage field tends to be harder, and greater stubble and residue on soil surface. Thus, the seeds can easily fall on the soil surface or stubble. Sufficient soil and seeds contact cannot be obtained. Hence, a low seed germination rate and emergence rate can occur ${ }^{[5,6]}$. Hence, the CHCSD should be provided with a seed furrow opener that can effectively implement furrowing and stubble cutting and removal.

Various studies have been conducted to evaluate the suitability of various types of furrow openers for no-tillage conditions. In addition to the conventional no-tillage openers of acute and obtuse angles, in-depth studies of furrow openers have also been conducted. A variety of new openers targeted towards different farming requirements and soil conditions have also been developed ${ }^{[7,8]}$. For example, Francetto et al. ${ }^{[9]}$ designed a new type of hoe furrow opener and conducted field trials in comparison with a traditional double-disc opener in a no-tillage system farm. The experimental results demonstrated that the hoe furrow opener is more efficient in the use of traction. Further, Kaleemullah ${ }^{[10]}$ has designed a wooden no-tillage opener having strong wear resistance under greater soil moisture and deeper fertilization conditions. Thus, this device is suitable for working in wet soil and deep furrowing conditions. Seidi et al. ${ }^{[11]}$ made a modified opener through adding two horizontal mini disks to an offset double-disk opener and performed a comparison experiment between the modified opener and offset double-disk opener in soil bin with heavy residues. The results indicated that in heavy residues soil some broken residue was pushed by the offset 
double-disk opener into seed furrow but the seed furrow of modified opener was clean. In addition, Vamerali et al. ${ }^{[12]}$ have designed a new wide-winged opener. Its performance was compared with the double disc opener through the experiment. The results concluded that the wide-winged opener can lead to higher soil-residue mixing on the seeding band, with a higher soil looseness efficiency at a buried depth of $5 \mathrm{~cm}$.

Along with the furrow opener design, studies on the furrowing and stubble cutting performance of the no-tillage furrow opener have also been conducted. Sawant et al. ${ }^{[13]}$ tested four types of furrow openers at three forward speeds on maize stalk residue soil: an inverted T-type furrow opener with plain rolling coulter, a single disk furrow opener, a double disk furrow opener and a double disk furrow opener with plain rolling coulter. The results showed that maize stalk residue cutting was more effective at all forward speeds with the double disk furrow opener with plain rolling coulter than others. In addition, Ahmad et al. ${ }^{[14]}$ experimentally evaluated the straw cutting performances of double disc furrow openers in a paddy field, considering different diameters, working depths and forwarding speeds. Their results reveal that a double disc opener of $450 \mathrm{~mm}$ in diameter provided the highest straw cutting efficiency at $90 \mathrm{~mm}$ working depth. Similarly, Bianchini et al. ${ }^{[15]}$ have examined the performance of smooth disc-type, notched disc-type, and toothed-type disc openers with diameter of $610 \mathrm{~mm}$ for cutting sugarcane straw. And the experimental results indicate that the required traction force of the smooth disc-type opener was larger than those of the other two openers for cutting off straw, but the cutting efficiency was poor. Zhang et al. ${ }^{[16]}$ designed key parameters of tine furrow opener and performed an experiment under no-till conditions, and the results showed that the rake angle, cutting edge thickness and cutting edge curve had significant effects on the cross-sectional shape of seeding furrow and the cutting efficiency of surface straw. Other researchers in multiple studies have concluded that the sliding knife opener is more energy-saving than other openers in cutting straw, while the cutting resistance gradually increases with decreased sliding angle of the sliding knife opener and gradually decreases with decreased friction angle of $\mathrm{it}^{[17-19]}$.

In all previous studies, furrow openers were developed as an independent drilling assembly. ${ }^{[20]}$ However, in the multiple CHCSD, the furrow opener construction space is limited. Therefore, in the current study, a small-sized sliding knife notch-type disc opener is designed and field experiments are conducted for performance evaluation. The results are compared with those for conventional modified small-sized disc furrow openers under no-tillage conditions.

\section{Materials and methods}

\subsection{Requirements for developing small-sized disc furrow openers}

The multi-purpose CHCSD was developed for harvesting and seeding in a one-pass operation which significantly decreased work times of field machines, led to the minimum soil disturbance and reduced fuel consumption. In addition, the soil was mulched after seeding and the excessive straw was gathered in a ditch, satisfying the conservative needs for sustainable agriculture. The main part of the CHCSD is a full-feed combine harvester (Guyuan 4LL-1.8). The ditching and straw-collecting system as well as the seeding system are integrated with the harvester. As illustrated in Figure 1, the ditching and straw-collecting system consists of a straw-collecting ditch opener that opens a ditch and then straw falls into the ditch and is placed there through a straw channel located at the harvester tail. The seeding system includes a seed box, grooved-wheel seed-metering device, seed transporting tube, furrow opener, soil throwing board and press wheel. Among them, the seed box, grooved-wheel seed-metering device, seed transporting tube and furrow opener are installed behind the header of the combine harvester, and their positions from top to bottom are the seed box, grooved-wheel seed-metering device, seed transporting tube and furrow opener; the soil throwing board is installed above the straw-collecting ditch opener and the press wheel installed behind it.

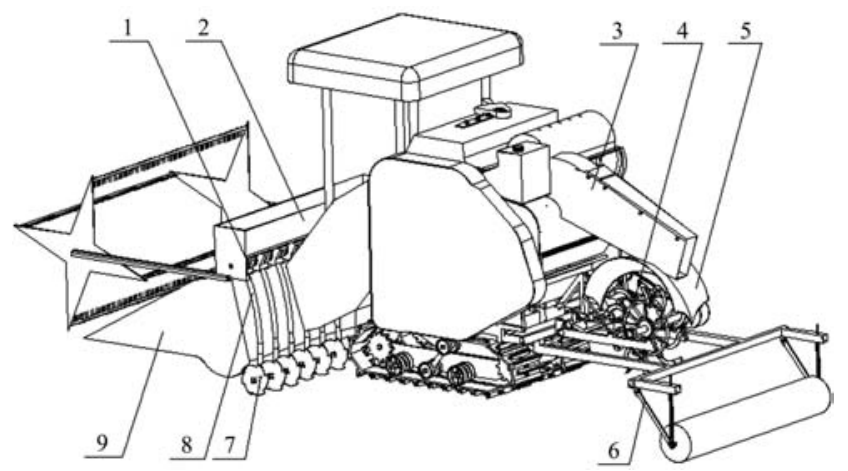

1. Grooved-wheel seed-metering device 2. Seed box 3. Straw channel 4. Straw-collecting ditch opener 5. Soil throwing board 6. Press wheel 7. Furrow-opener Installation position 8. Seed transporting tube 9. Cutting table

Figure 1 Schematic diagram of the multi-purpose CHCSD for combined harvesting with straw burying and no-till seeding

During functioning of the CHCSD, grain harvesting and threshing are completed first. Then, the threshed straw is discharged from the straw channel to fall into the straw-collecting ditch opened by the straw-collecting ditch opener. Thus, the process of returning the straw to the field is completed. Meanwhile, the grooved-wheel seed-metering device drills the seeds from the seed box falling in the furrow opened by the furrow opener. The straw-collecting ditch opener rotates at high speed to throw the soil colliding with the soil throwing board, so as to throw soil to cover the tops of the seeds after soil collides with the soil throwing board. Finally, the press wheel at the end of the machine compacts the soil and covers the seeds to complete the seeding process.

To satisfy the furrowing seed furrow requirements applicable to the CHCSD under no-tillage seeding conditions and the limited installation space of furrow opener as compact structure of CHCSD, the height and width dimensions of furrow opener should not be more than $160 \mathrm{~mm}$. Furthermore, the furrowing and stubble cutting ability of the furrow opener should be robust to suit the features of no-tillage field, which has considerable heavy stubble and hardened surface soil.

The disc-type furrow opener is commonly utilized in the grain planter because of its simple structure, superior soil-penetrating properties, smaller soil disturbance, and higher residue cutting performance. Therefore, according to the installation space and furrowing requirements of CHCSD, designed small-sized disc furrow openers with diameters of less than $160 \mathrm{~mm}$ and having furrowing and stubble-cutting performance were examined in this study.

\subsection{Design and description of small-sized disc furrow openers}

Both the smooth disc type and notched disc type furrow openers are conveniently used tools for seeding. However, the slide-cutting principle has not been introduced to the design on the tool's cutting notch, which is particularly important for enhanced 
straw cutting for no-till seeding in heavy crop residue conditions, which are common in the R-W rotating areas ${ }^{[21,22]}$. Therefore, small-sized disc furrow openers were designed, and a sliding knife notch-type disc opener (SKO), in particular, was designed with an emphasis on its functional cutting edges ${ }^{[23]}$.

\subsubsection{Design of sliding knife notch-type disc opener}

To improve the SKO stubble cutting ability in a no-tillage field, a notch similar to a sliding knife was designed around the cutting edge of the opener, as shown in Figure 2. In this study, the base circle diameter $D_{j}$ was $160 \mathrm{~mm}$ and the base circumference length was $C_{j}=\pi D_{j}$; thus, $C_{j}=502.4 \mathrm{~mm}$ was obtained. Further, the disc opener radius $R_{j}$ was $80 \mathrm{~mm}$ and the number of notches was labeled $N$. As too many or few notches will lead to a decrease of cutting capacity, to ensure that the opener notch had a certain cutting capacity for the root stubble, the notch arc length was designed to be equal to the opener radius. $N$ was calculated from the relation

$$
N=\frac{C_{j}}{R_{j}}
$$

where, $N=6.28$ was obtained in this case. Then, $N$ was rounded to $N=6$.

The $O$ point (Figure 2) corresponds to the base circle center. In order to increase the straw residue cutting capacity at the edge of notch, the notch arc was established as the arc on six eccentric circles relative to the base circle with diameters equal to $D_{j}$ and the circle centers being labeled $O_{1}-O_{6}$ in order. According to the agronomic requirement that the furrowing depth is $\geq 2 \mathrm{~cm}$, the offset distance $L$ of the eccentric circle center and the base circle center was $1 / 6 D_{j}$. The six eccentric circles were circulated around the $O$ point, intersecting with the base circle at six points labeled $a-f$. The base circle radii extended to these six points, being labeled $O a, O b, O c, O d, O e$, and $O f$, respectively. The six radii, $\mathrm{Oa}, \mathrm{Ob}, \mathrm{Oc}, \mathrm{Od}, \mathrm{Oe}$, and $O f$, across the six eccentric circles intercepted obtaining six arcs, $A f, F e, E d, D c, C b$ and $B a$ (Figure 2), and six arcs with six radii upper line segments, $A a, B b, C c, D d, E e$, and $F f$, yield the notch shape similar to the sliding knife, as indicated by the bold shape in Figure 2.

To create an SKO that opens a furrow of a certain width, the opener was designed to have a certain sidewise curvature, as shown in Figure 2. According to the agronomical requirements, the opener width must be $2-3 \mathrm{~cm}$. Thus, the vertical distance $B_{i} C_{i}$ from the bottom to the center of the disc with curvature was set to $20 \mathrm{~mm}$. The $O C_{i}$ distance was the base radius of $80 \mathrm{~mm}$; thus, $O B_{i}$ was $82.5 \mathrm{~mm} . \quad O A_{i}$ was the curvature diameter of the $B_{i} D_{i}$ arc; as the triangles $A_{i} B_{i} O$ and $O C_{i} B_{i}$ were similar, and the disc curvature diameter $O A_{i}$ of the opener was $3514.5 \mathrm{~mm}$.

Through designs, the cutting edge of the SKO was more conducive to entering soil during the rotation process than the others. The stubble was cut by the notch similar to the sliding knife by gradual insertion into the soil layer, which slashed the root stubble to effectively sever the raw stubble and residue, thereby playing a stubble-cutting role.
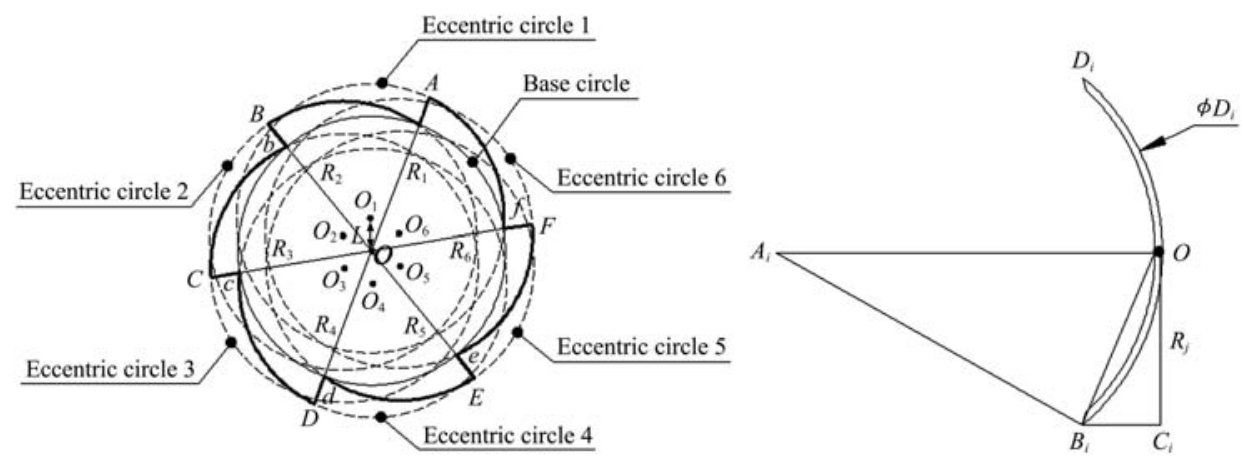

Figure 2 Schematic diagram of SKO

\subsubsection{Modified notch-type disc opener}

The entire structure of the modified notch-type disc opener (MNO) is identical to that of the traditional rake disc type opener. In this study, the main parameters were as follows. As in the previous SKO, the base circle diameter $D_{1}$ was $160 \mathrm{~mm}$ and the number of notches $N_{1}$ was 6 . The notch arc diameter was the same as $D_{1}$ and the distance $L_{1}$ from the notch arc center to the base circle center was $1 / 3 D_{1}$. In addition, the sidewise curvature of the MNO and SKO were consistent, with a curvature diameter of $3514.5 \mathrm{~mm}$. The MNO contour is shown by the bold shape in Figure 3.

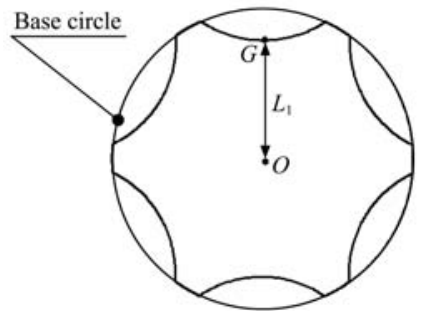

Figure 3 Schematic diagram of MNO

2.2.3 Smooth-type disc opener

The entire structure of the smooth-type disc opener (SDO) is identical to that of the traditional single-disc opener. In this study, the main parameters for this design were as follows. Again, the base circle diameter $D_{2}$ was $160 \mathrm{~mm}$. The SDO sidewise curvature was consistent with the SKO, having a curvature diameter of $3514.5 \mathrm{~mm}$.

\subsection{Fabrication of small-sized disc furrow openers}

All three types of small-sized disc furrow openers with diameter of $160 \mathrm{~mm}$ mentioned above were manufactured in this study. As the installation shaft of opener requires, the diameter of the opener should be no less than $120 \mathrm{~mm}$ in order that the opener can function normally. Hence, in order to study the influence of diameter on the work performance of the small-sized disc furrow openers, the same three types openers with diameter of $120 \mathrm{~mm}$ and small-sized disc furrow openers with diameter of $160 \mathrm{~mm}$ were manufactured to act as a control group. All openers were manufactured using manganese steel and a quenching treatment. A photograph of the fabricated openers is shown in Figure 4.

\subsection{Field experiments on small-sized disc furrow openers}

Field experiments were conducted for the fabricated small-sized disc furrow openers, to examine the furrowing and stubble cutting ability of the openers. 


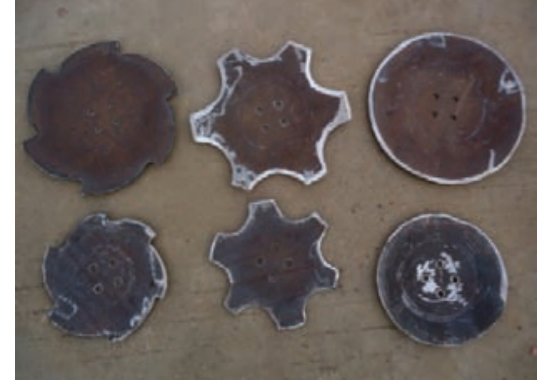

Note: openers shown on the top and bottom are $160 \mathrm{~mm}$ and $120 \mathrm{~mm}$ in diameters, respectively.

Figure 4 Photograph of small-sized disc furrow openers

\subsubsection{Experimental materials}

SKOs, MNOs, and SDOs with diameters of $160 \mathrm{~mm}$ and $120 \mathrm{~mm}$ were fitted to the CHCSD that provided the power used to operate the openers. During the experiment, the small-sized disc furrow openers were installed at the Installation location of the furrow opener, under the seed transporting tube of the CHCSD (as shown in Figure 1). Furrowing and stubble cutting performance evaluation was then conducted for the different openers.

\subsubsection{Experimental field conditions}

The furrowing and stubble cutting experiment was conducted in the experimental field of Huanghai Farm, Yancheng City, Jiangsu Province, in April 2016. The experimental field covers an area of $5.28 \mathrm{~m} \times 103 \mathrm{~m}$ and the field soil was clay loam composed mainly of clay, silt and sand. Meanwhile, rice straw was laid on the soil surface for the furrowing and stubble cutting experiment. The main parameters of the experiment are listed in Table 1.

Table 1 Main parameters of test field

\begin{tabular}{lc}
\hline \multicolumn{1}{c}{ Parameters } & Value \\
\hline Bulk density $/ \mathrm{t} \cdot \mathrm{m}^{-3}$ & 1.31 \\
Wet density $/ \mathrm{t} \cdot \mathrm{m}^{-3}$ & 1.8 \\
Soil texture & Clay loam \\
Dry basis soil moisture content $/ \%$ & 28.98 \\
Soil cohesion $/ \mathrm{kPa}$ & $45.01(0-2 \mathrm{~cm}), 53.44(4-6 \mathrm{~cm})$, \\
Soil con index $/ \mathrm{kPa}$ & $64.16(8-10 \mathrm{~cm})$ \\
Straw average length $/ \mathrm{cm}$ & $695(0 \mathrm{~cm}), 994(5 \mathrm{~cm}), 1207(10 \mathrm{~cm})$ \\
Straw moisture content $/ \%$ & 42.1 \\
Breaking force of the $\mathrm{straw} / \mathrm{N} \cdot \mathrm{mm}^{-2}$ & 16.14 \\
\hline
\end{tabular}

\subsubsection{Experiment design}

During the experiment, the small-sized disc furrow openers were installed in the CHCSD in turn, being operated at an average speed of $0.3 \mathrm{~m} / \mathrm{s}$. The depth in soil of the small-sized disc furrow openers was approximately $3 \mathrm{~cm}$. An operational length of $20 \mathrm{~m}$ furrowing and stubble cutting was achieved by the opener in each trip. Each experiment was conducted in triplicate. The field experiment process is described in Figure 5.

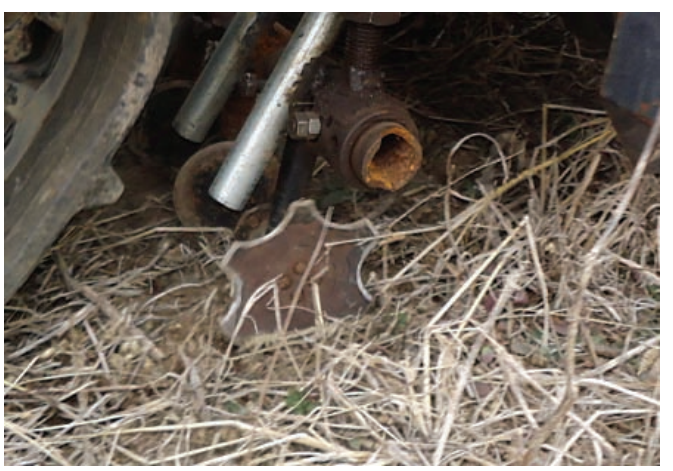

Figure 5 Schematic diagram of field test for furrow opener

\subsection{Furrow-type dimension determination}

After completion of each experimental trip, 50 points were randomly selected on a $20 \mathrm{~m}$ trip for furrow width and depth measurement with a ruler. The furrow depth was the distance from the soil surface to the furrow bottom after furrowing, and the furrow width was the width of the soil surface opening after furrowing.

\subsection{Stubble cover rate determination}

Before the experiment was initiated, a sampling area of $20 \mathrm{~m}$ in length and $4 \mathrm{~cm}$ in width was selected and the length of each straw in that area was measured. The cumulative length $H$ of all straw on the soil surface in the sampling area was then calculated. During the furrowing process, the openers were preferably located at the center of the straw on the sampling area. After the furrowing process, the cumulative length $H_{1}$ of all straw on the soil surface in the sampling area was recalculated. For all field experiments the stubble cover rate $Y$ was determined from the relation $^{[24]}$

$$
Y=\frac{\left(H-H_{1}\right)}{H} \times 100 \%
$$

The ability of small-sized disc furrow openers to remove residue outside from the furrow and seeding band was evaluated by examining the stubble cover rate.

\subsection{Stubble cutting rates determination}

The stubble cutting rate is an important index for evaluating the working performance of the furrow opener in a no-tillage seeding environment. During operation, the opener should cut straw at the furrowing and seeding area to create suitable conditions for seeds to fall smoothly into the furrow. An experiment was conducted to study the small-sized disc furrow openers' stubble cutting properties for different straw orientations.

In the experimental field, a fixed number of rice straw pieces were placed according to certain rules. That is, straw pieces were divided into four groups corresponding oriented in four directions: perpendicularity, $45^{\circ}$, and parallel to the advancing direction of the furrow opener, and in an irregular layout. In total, 600 pieces of straw were placed along each orientation, over a total length of $2 \mathrm{~m}$ (one trip). The straw having each orientation after placement was in a straight line, as shown in Figure 6. Note that, previously, Eltom et al. ${ }^{[25]}$ used the same method to study the furrowing and stubble cutting ability of the furrow plough. After straw placement, the small-sized disc furrow openers were installed in the CHCSD in turn. The furrowing and stubble cutting experiment was then performed, with the average forward speed of the CHCSD being $0.3 \mathrm{~m} / \mathrm{s}$ and the depth into soil of the small-sized disc furrow 
openers being approximately $3 \mathrm{~cm}$. Each opener passed through the center of the straw, and the number of cut pieces of straw was examined after the experiment. Hence, the stubble cutting rates of the small-sized disc furrow openers were calculated for straw in different orientations according to following equation:

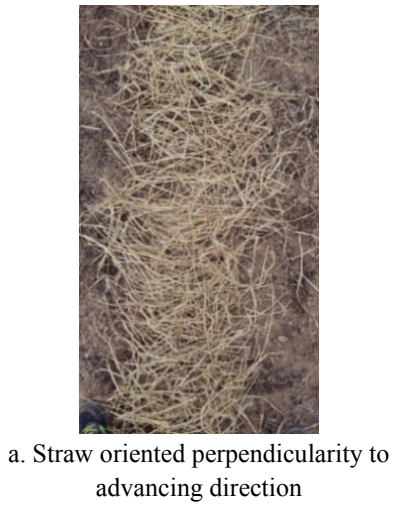

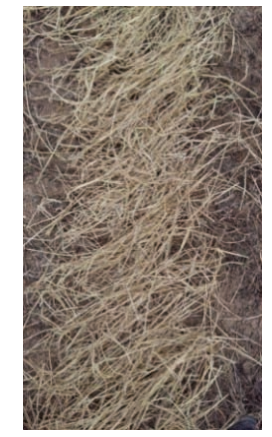

b. Straw oriented $45^{\circ}$ angle to advancing direction

$$
P=\frac{Z_{1}}{Z} \times 100 \%
$$

where, $P$ is the stubble cutting rates; $Z$ is the total numbers of pieces of straw per trip, and $Z_{1}$ is the number straw pieces cut per trip.
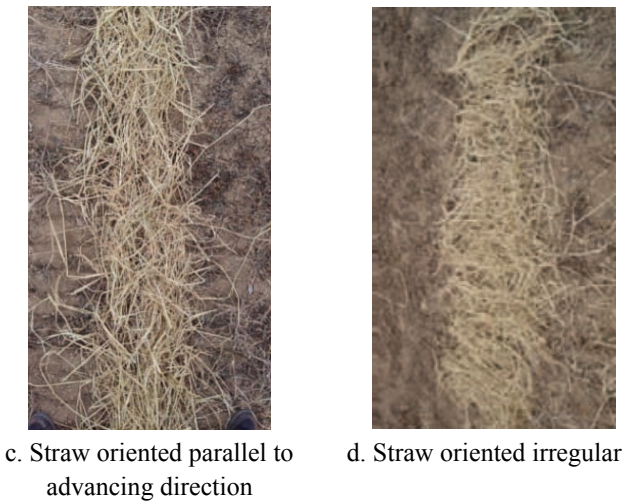

d. Straw oriented irregularly advancing direction

Figure 6 Schematic diagram of straw placement with different orientations

\section{Results}

\subsection{Furrow dimension and stubble cover rate experimental results for small-sized disc furrow openers}

In the field experiment, the furrow dimensions obtained using the small-sized disc furrow openers were measured. The results

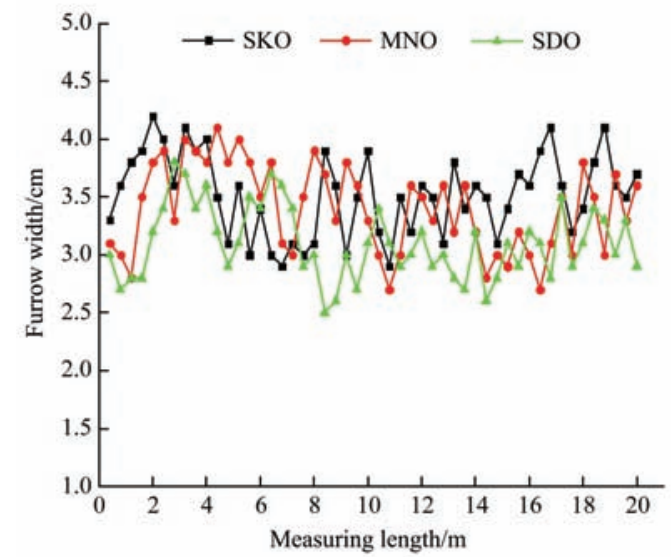

a. Furrow depths for small-sized disc furrow openers with $160 \mathrm{~mm}$ in diameter

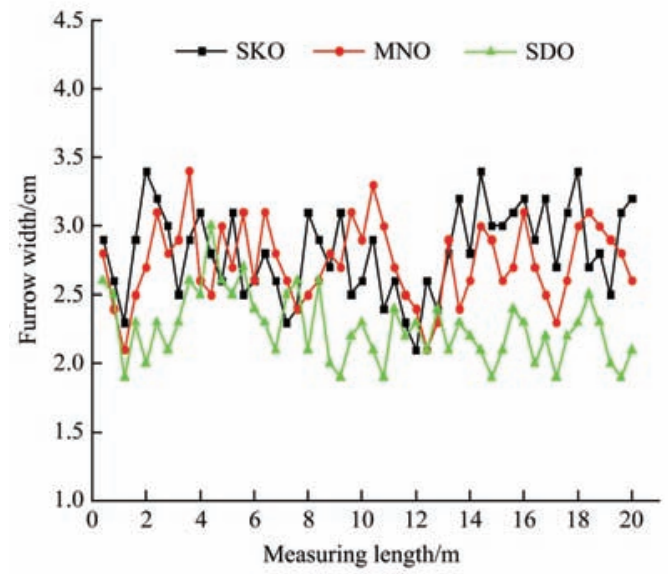

c. Furrow depths for small-sized disc furrow openers with $120 \mathrm{~mm}$ in diameter of furrow depths and widths created by the SKOs, MNOs, and SDOs with diameters of $120 \mathrm{~mm}$ and $160 \mathrm{~mm}$ at 50 consecutive measurement points along the $20 \mathrm{~m}$ travel distance are plotted in Figure 7. The average furrow depth and width values are listed in Table 2 .

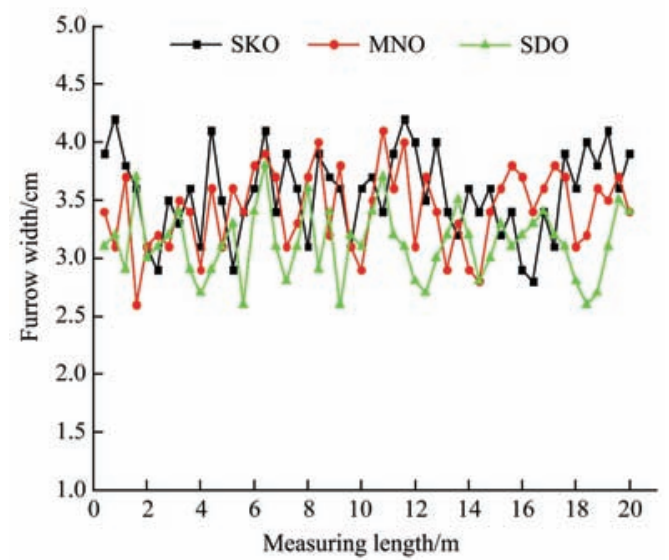

b. Furrow widths for small-sized disc furrow openers with $160 \mathrm{~mm}$ in diameter

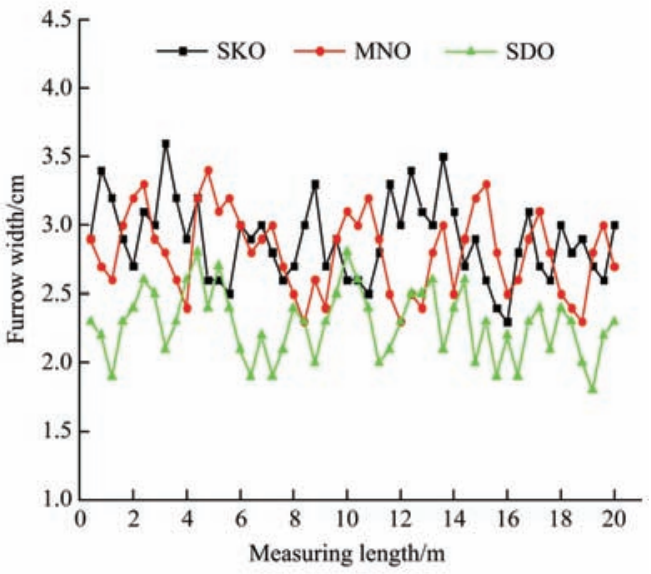

d. Furrow widths for small-sized disc furrow openers with $120 \mathrm{~mm}$ in diameter
The results of the field experiment show that the furrow depths and widths created by the small-sized disc furrow openers with $160 \mathrm{~mm}$ diameter were greater than those by openers with diameter of $120 \mathrm{~mm}$. Of the three opener designs, the SKO yielded the largest furrow depth and width. The furrow depth and width of the SKO with diameter of $160 \mathrm{~mm}$ were $3.52 \mathrm{~cm}$ and $3.56 \mathrm{~cm}$, respectively. The furrow depth and width of the SKO satisfies the requirements of furrow dimension for no-tillage 
seeding. The standard deviation of the furrow depth and width results for each of the small-sized disc furrow openers was less than 0.5 and the variable coefficient was less than $15 \%$; thus and a stable furrow depth and width was obtained throughout the trip for each opener.

Table 2 Experimental results for small-sized disc furrow openers examined herein

\begin{tabular}{ccccccc}
\hline & \multicolumn{3}{c}{ Furrow depth } & & \multicolumn{3}{c}{ Furrow width } \\
\cline { 2 - 3 } \cline { 5 - 6 } Opener type & $\mathrm{MV} * \mathrm{~cm}$ & $\mathrm{SD}^{*}$ & $\mathrm{CV} * \%$ & $\mathrm{MV} / \mathrm{cm}$ & $\mathrm{SD}$ & $\mathrm{CV} / \%$ \\
\hline $\begin{array}{c}\text { SKO with 160-mm } \\
\quad \text { diameter }\end{array}$ & $3.52 \mathrm{a}$ & 0.35 & 10.07 & $3.56 \mathrm{a}$ & 0.37 & 10.30 \\
$\begin{array}{c}\text { MNO with 160-mm } \\
\text { diameter }\end{array}$ & $3.40 \mathrm{a}$ & 0.38 & 11.26 & $3.42 \mathrm{a}$ & 0.34 & 10.09 \\
$\begin{array}{c}\text { SDO with 160-mm } \\
\text { diameter }\end{array}$ & $3.10 \mathrm{~b}$ & 0.31 & 10.12 & $3.13 \mathrm{~b}$ & 0.29 & 9.43 \\
$\begin{array}{c}\text { SKO with 120-mm } \\
\text { diameter }\end{array}$ & $2.82 \mathrm{~cd}$ & 0.32 & 11.42 & $2.89 \mathrm{~cd}$ & 0.29 & 10.01 \\
$\begin{array}{c}\text { MNO with 120-mm } \\
\text { diameter }\end{array}$ & $2.73 \mathrm{~d}$ & 0.29 & 10.62 & $2.81 \mathrm{~d}$ & 0.30 & 10.62 \\
$\begin{array}{c}\text { SDO with 120-mm } \\
\text { diameter }\end{array}$ & $2.26 \mathrm{fg}$ & 0.25 & 10.93 & $2.28 \mathrm{f}$ & 0.25 & 10.88 \\
\hline
\end{tabular}

Note: *MV: mean value; SD: standard deviation; CV: coefficient of variance

Analysis of variance (ANOVA) of the furrow depth and width results obtained in the field experiments was performed. ANOVA revealed that, although the furrow depth value for the SKO with diameter of $160 \mathrm{~mm}$ was greater than that of the MNO with the same diameter, there was no significant difference $(p>0.05)$. The furrow depths yielded by the SKO and MNO with $160 \mathrm{~mm}$ in diameter were both significantly higher than that of the SDO with the same diameter $(p<0.05)$. The furrow depth obtained for the SKO with diameter of $120 \mathrm{~mm}$ was higher than that for the MNO with the same diameter; however, no significant difference was obtained $(p>0.05)$. The furrow depths of the SKO and MNO with diameter of $120 \mathrm{~mm}$ were found to be significantly higher than that of the SDO with the same diameter $(p<0.05)$. As regards the furrow width, that of the SKO with diameter of $160 \mathrm{~mm}$ was greater than that of the MNO with the same diameter; however, no significant difference was observed $(p>0.05)$. The furrow widths of the SKO and MNO with diameter of $160 \mathrm{~mm}$ were significantly higher than that of the SDO with the same diameter $(p<0.05)$. The furrow width of the SKO with diameter of $120 \mathrm{~mm}$ was greater than that of the MNO of the same diameter; however, no significant difference was found $(p>0.05)$. The furrow widths of SKO and MNO with diameter of $120 \mathrm{~mm}$ were significantly higher than that of the SDO with the same diameter $(p<0.05)$.

The experimental results for the stubble cover rate are plotted in Figure 8. The stubble cover rates of the SKO, MNO, and SDO with diameter of $160 \mathrm{~mm}$ were $62.5 \%, 55.1 \%$, and $39.6 \%$, respectively. The stubble cover rates of the SKO, MNO, and SDO with diameter of $120 \mathrm{~mm}$ were $48.2 \%, 41.5 \%$, and $28.3 \%$, respectively. Hence, the stubble cover rate was highest for the SKO with diameter of $160 \mathrm{~mm}$; this opener also exhibited the greatest capability for straw stubble removal from the furrowing and seeding area. For openers of the same type, the stubble cover rate of those with diameter of $160 \mathrm{~mm}$ was greater than those with diameter of $120 \mathrm{~mm}$ diameter. As regards small-sized disc furrow openers of the same diameter, the stubble cover rate of the SKO was found to be greater than that of the MNO, with the SDO having the lowest stubble cover rate.

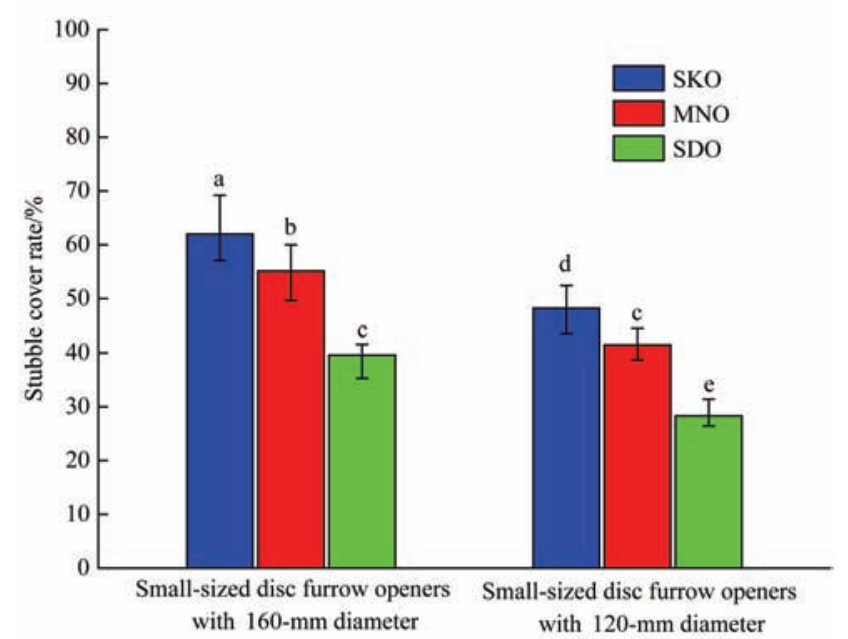

Figure 8 Test results of stubble cover rate

\subsection{Stubble cutting rates of small-sized disc furrow openers}

After the experiment, the stubble cutting efficiencies of the openers were determined. As an example, Figure 9 shows the stubble-cutting effect of the SKO with diameter of $160 \mathrm{~mm}$, for straws positioned irregularly. It is apparent that the opener created a clear furrow, with a certain number of straw stubble pieces being cut. The straw pieces surrounding the furrow and seeding area were moved to either side to a certain extent, thereby reducing the number of seeds that would fall on straw stubble rather than soil.

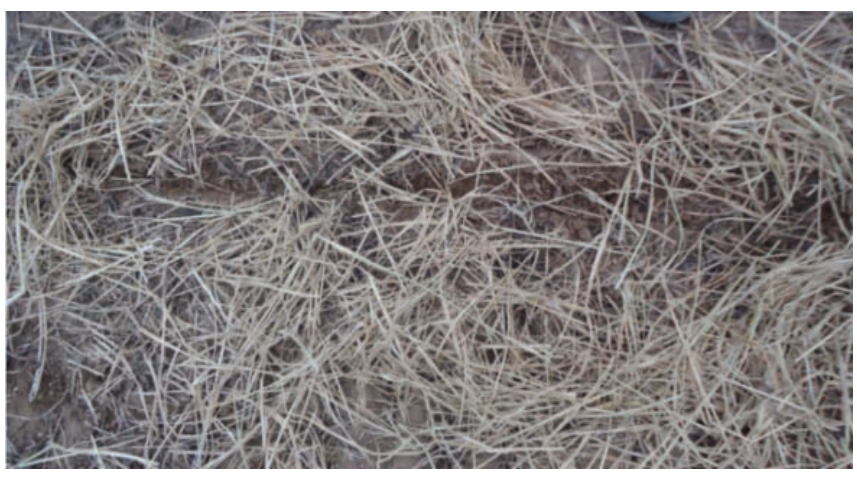

Figure 9 Photograph of stubble cutting effect for small-sized disc furrow openers

Figure 10 shows the stubble cutting rates of the examined openers for all of the straw orientations. It is apparent that the stubble cutting rates of the small-sized disc furrow openers with diameter of $160 \mathrm{~mm}$ were better than the small-sized disc furrow openers of the same type with diameter of $120 \mathrm{~mm}$ to any of straw orientations. Moreover, for irregularly placed straw, the stubble cutting rates of the SKO, MNO, and SDO with diameter of $160 \mathrm{~mm}$ were $23.3 \%, 22.8 \%$, and $31.5 \%$ more than those with diameter of $120 \mathrm{~mm}$, respectively. Hence, the bigger diameter could enhance stubble cutting ability to small-sized disc furrow opener.

It can be concluded from the experimental results shown in Figure 10 that, for small-sized disc furrow openers of the same diameter, the stubble cutting rates of the SKO were always higher than those of the MNO and SDO, with the SDO having the lowest stubble cutting rates in any one of the straw placement orientations. For irregularly placed straw, the stubble cutting rates of the SKO, MNO and SDO with diameter of $160 \mathrm{~mm}$ were $61.7 \%, 52.5 \%$, and $42.3 \%$ respectively, and the stubble cutting rates of the same openers with diameter of $120 \mathrm{~mm}$ were $38.4 \%, 29.7 \%$, and $10.8 \%$ 
respectively. Thus, the shape of the disc cutting edge directly affected the stubble cutting efficiency of the small-sized disc furrow openers. The notch shape similar to the sliding knife of the SKO improved the straw stubble cutting ability, as the stubble could be gradually inserted into the soil for cutting. Although the MNO also had an arc-shaped notch cutting edge, it had no slide cutting efficiency like that of the SKO. So the stubble cutting rates of the MNO were lower than those of SKO. Further, the stubble cutting rates of the traditional unnotched SDO were significantly lower than those of the other two types. And the fact that the small-sized disc furrow openers having cutting edge with notch type would advance the stubble cutting ability was validated.

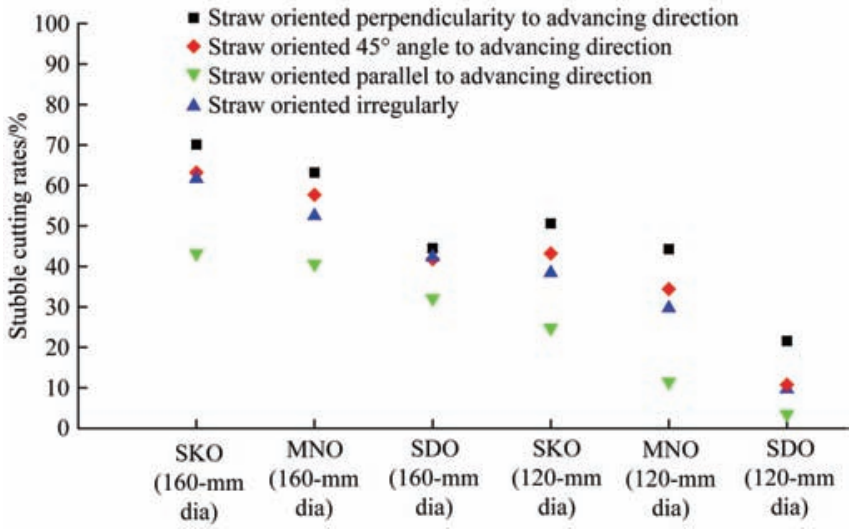

Figure 10 Test results of stubble cutting rates for small-sized disc furrow openers

Moreover, Figure 10 shows that, for straw with four different orientations, the stubble cutting rates of the small-sized disc furrow openers differed. For the three straw placement orientations excluding irregular placement, the stubble cutting rates performance of the small-sized disc furrow openers could be ordered as straw oriented parallel to the advancing direction was the highest, and straw oriented perpendicularity to the advancing direction was the lowest, indicating that the small-sized disc furrow openers were more likely to cut stubble having a larger angle relative to the advancing direction.

\section{Discussion}

The furrow dimensions are key to developing proper seedbed circumstance. Adequate seedbed circumstance is required for good germination, emergence, and crop yield. The results of furrow dimensions of small-sized disc furrow openers indicated that increased disc diameter, the furrow width and depth also increased, and the results were same as other disk openers ${ }^{[26]}$. Further, for openers with the same diameter, the furrow depth and width of the SKO was greater than that of the other opener types. This finding is in agreement with previous studies indicating that an opener with a slide blade could increase furrow depth and width $^{[27]}$. In addition, the field experiments have clearly proven that the SKO performs significantly better than the other small-sized disc furrow openers, when used in the CHCSD for no-tillage sowing of wheat and rice.

The furrow opener is an important component of a seed drill or a planter. In general, a furrow opener cuts a furrow and allows deposition of seeds or seedlings before they are partially covered with soil. The experimental results related to stubble cover rate obtained in this study indicate that an opener with a larger diameter has superior ability for straw stubble removal from the furrow and seeding area; this is directly associated with higher efficiency in the conservation tillage. A similar trend had also been reported previously for oat stubble ${ }^{[28]}$. That study was conducted using field experiments for no-tillage seeder openers with different diameters, and it was found that a larger opener diameter corresponded to greater stubble-clearing efficiency, when the diameter was within a certain range. The study of the stubble cover rate indicated that the SKO had greater ability for straw stubble removal from the furrow and seeding area. Another similar study on crop stubble has also been reported previously ${ }^{[29]}$. That study reported on the stubble cutting efficiency of three seed furrow openers. The results confirmed that the angle-notched disc opener had superior performance for stubble cutting than non-notched disc opener and hoe-type openers.

The investigation of the stubble cutting efficiency conducted in this study has indicated that, for small-sized disc furrow openers, a larger opener diameter is more conducive for stubble cutting. A similar study conducted in a no-tillage paddy soil environment has also been reported previously ${ }^{[30]}$. That investigation confirmed that a larger double-disc opener diameter yields better stubble cutting efficiency. The maximum stubble cutting efficiency was obtained when the diameter was increased to $450 \mathrm{~mm}$. The study of stubble cutting efficiency declared that the maximum performance was obtained for the SKO, because of its unique circular cutting edge notches. These notches act like knives with the support of the soil surface, cutting the crop residue and opening the furrow more effectively than the other types of furrow openers. The experimental facts reported above were found to be in agreement with the dynamic performance of the disc furrow openers in existing research ${ }^{[31]}$.

\section{Conclusions}

In this study, to satisfy the requirements of no-tillage seeding and furrowing, an SKO for a multi-functional CHCSD was designed. This SKO possesses circular cutting edge notches similar to a sliding knife that is curved to enhance its furrowing and stubble cutting performance.

Field experiments were conducted using three different types small-sized disc furrow openers with two different sizes. Hence, it was confirmed that the furrow depths and widths yielded by openers with diameter of $160 \mathrm{~mm}$ were bigger than those created by openers of the same type and with $120 \mathrm{~mm}$ diameter. The furrow depth and width of the SKO with diameter of $160 \mathrm{~mm}$ were $3.52 \mathrm{~cm}$ and $3.56 \mathrm{~cm}$, respectively, and bigger than those of the other small-sized disc furrow openers examined in this study. These dimensions satisfy the requirements for a no-tillage seeding and furrowing system.

The results of the field experiments concerning the stubble cover rate provided by each opener proved that the rates yielded by the small-sized disc furrow openers with diameter of $160 \mathrm{~mm}$ were higher than those of openers of the same type and with diameter of $120 \mathrm{~mm}$. The stubble cover rate of the SKO with diameter of $160 \mathrm{~mm}$ was the highest and $62.5 \%$; thus, it had the greatest ability to remove the straw stubble from the furrowing and seeding area.

Investigation of the stubble cutting performance of the small-sized disc furrow openers indicated that, for openers with the same diameter, the straw stubble cutting ability can be ranked as follows: SKO > MNO > SDO. Further, for small-sized disc furrow openers, straw oriented perpendicularity to the opener advancement direction is the most easily cut, whereas straw parallel to the advancement direction is difficult to be cut off. 


\section{Acknowledgements}

The research was financially supported by the National Science and Technology Support Program (No.2013BAD08B04). The authors are thankful to Mr. He Yanguo for providing the experimental field at the Huanghai farm.

\section{[References]}

[1] Farooq M, Nawaz A. Weed dynamics and productivity of wheat in conventional and conservation rice-based cropping systems. Soil Till. Res., 2014; 141: 1-9.

[2] He J, Li H W, McHugh A D, Wang Q J, Li H, Rasaily R G, et al. Seed zone properties and crop performance as affected by three no-till seeders for permanent raised beds in Arid Northwest China. Journal of Integrative Agriculture, 2012; 11(10): 1654-1664.

[3] López-Garrido R, Madejón E, León-Camacho M, Girón I, Moreno F, Murillo J M. Reduced tillage as an alternative to no-tillage under Mediterranean conditions: A case study. Soil Till. Res., 2014; 140: 40-47.

[4] Qin K, Ding W M, Fang Z C, Du T T, Zhao S Q, Wang Z. Design and experiment of seed system for harvest ditch and stalk-disposing machine. Transactions of the CSAM, 2017; 48(5): 54-62. (in Chinese)

[5] Jia H L, Jiang X M, Yuan H F, Zhuang J, Zhao J L, Guo M Z. Stalk cutting mechanism of no-tillage planter for wide/narrow row farming mode. Int J Agric \& Biol Eng, 2017; 10(2): 26-35.

[6] Iqbal M, Muneer A M, Hussain K A, Umair M. Evaluation of the energy efficient zone disk drill for sowing of wheat after harvesting paddy crop. Int. J. Agric. Biol., 2012; 14: 633-636.

[7] Singh K P, Agrawal K N, Jat D, Kumar M, Kushwaha H L, Shrivastava P, et al. Design, development and evaluation of furrow opener for differential depth fertilizer application. Indian Journal of Agricultural Sciences, 2016; 86(2): 250-255.

[8] Altuntas E, Ozgoz E, Taser F, Tekelioglu O. Assessment of different types of furrow openers using full automatic planter. Asian journal of plant sciences, 2006; 5(3): 37-42.

[9] Francetto T R, Alonço A S, Carpes D P, Machado O D , Becker R S, Brandelero C. Specific demands to the traction of cutting discs and furrow openers for the no-tillage system. Aust J Crop Sci, 2016; 10(7): 1040-1046.

[10] Kaleemullah S.Development of a low-cost ferticum seed drill. AMA-Agri. Mech Asia Afri., 1997; 28: 26-28.

[11] Seidi E, Abdollahpour S H, Javadi A, Moghaddam M. Effects of novel disk-type furrow opener used in no-tillage system on microenvironment of seed. Am. J. Agri. \& Biol. Sci., 2010; 5(1): 1-6.

[12] Vamerali T, Bertoccob M, Sartori L. Effects of a new wide-sweep opener for no-till seeder on seed zone properties and root establishment in maize (Zea mays L.): A comparison with double-disk opener. Soil Till. Res., 2006; 89:196-209.

[13] Sawant C, Kumar A, Mani I, Singh J K. Soil bin studies on the selection of furrow opener for conservation agriculture. J Soil Water Conserv., 2016; 15(2): 107-112.
[14] Ahmad F, Ding W M, Ding Q S, Hussain M, Jabran K. Forces and straw cutting performance of double disc furrow opener in no-till paddy soil. PloS One., 2015; 10(3): e0119648. DOI: 10.1371/journal.pone.0119648.

[15] Bianchini A, Magalhaes P. Evaluation of coulters for cutting sugar cane residue in a soil bin. Biosyst. Eng., 2008; 100: 370-375.

[16] Zhang X C, Li H W, Du R C, Ma S C, He J, Wang Q J, et al. Effects of key design parameters of tine furrow opener on soil seedbed properties. Int J Agric \& Biol Eng, 2016; 9(3): 67-80.

[17] Jia H L, Zheng J X, Yuan H F, Guo M Z, Wang W J and Jiang X M. Design and experiment of profiling sliding-knife opener. Transactions of the CSAE, 2017; 33(4): 16-24. (in Chinese)

[18] Solhjou A, Fielke J M, Desbiolles J M A. Soil translocation by narrow openers with various rake angles. Biosyst. Eng., 2012; 112: 65-73.

[19] Gu Y Q, Jia H L, Guo H, Zhao W G, Zhao X T. Design and experiment of sliding knife furrow openner. Chinese Journal of Mechanical Engineering, 2013; 44(2): 38-42. (in Chinese)

[20] Barr B J, Desbiolles M A J, Fielke, M J. Minimising soil disturbance and reaction forces for high speed sowing using bentleg furrow openers. Biosyst. Eng. 2016; 151: 53-64.

[21] Yang L, Zhang R, Gao N N, Cui T, Liu Q W, Zhang D X. Performance of no-till corn precision planter equipped with row cleaners. Int J Agric \& Biol Eng, 2015; 8(5): 15-25.

[22] Altikat S, Celik A, Gozubuyuk Z. Effects of various no-till seeders and stubble conditions on sowing performance and seed emergence of common vetch. Soil Till. Res., 2013; 126: 72-77.

[23] Sarauskis E, Masilionyte, L, Romaneckas K, Kriauciuniene Z, Jasinskas A. The effect of the disc coulters forms and speed ratios on cutting of crop residues in no-tillage system. Bulg. J. Agric. Sci., 2013, 19: 620-624.

[24] Su Y B, Dong Y, Li H W, He J, Wang Q J, Li H. Measuring system for residue cover rate based on automation threshold. J. Agri. Mech. Res., 2012; 8: 138-142

[25] Farid A E, Wei M D, Ding Q H. Field investigation of a trash-board tillage depth and low speed effect on the displacement and burial of straw. Catena, 2015; 133: 385-393.

[26] Zhao S, Chen Y. Seed distribution in soil and its effects on early plant growth. Appl. Eng. Agric., 2015; 31(3): 415-423.

[27] Naresh R K, Gupta R K, Kumar A, Sing B, Prakash S, Kumar S, et al. Direct-seeding and reduced-tillage options in the ice-wheat system of the Western Indo-Gangetic Plains. Int J Agr Sci, 2011; 7(1): 197-208.

[28] Doan V, Chen Y, Irvine B. Effect of residue type on the performance of no till seeder openers. Can. Biosyst. Eng., 2005; 47: 229-235.

[29] Munir M A, Iqbal M, MIran S. Evaluation of three seeder furrow openers mounted on a zone disk tiller drill for residue management, soil physical properties and crop parameters. Pak. J. Agri. Sci. 2012; 49: 349-355.

[30] Ahmad F, Ding W M, Ding Q D, Rehim A, Jabran K. Comparative Performance of Various Disc-Type Furrow Openers in No-Till Paddy Field Conditions. Sustainability, 2017; 9(7): 1143.

[31] Chaudhuri D. Performance evaluation of various types of furrow openers on seed drills: a review. Journal of Agricultural Engineering Research, 2001; 79(2): 125-137. 